\title{
Immunohistochemical characterization of lymphocyte and myeloid cell infiltrates in spirocercosis-induced oesophageal nodules
}

\author{
E. DVIR, ${ }^{1}$ J. P. SCHOEMAN, ${ }^{1}$ S. J. CLIFT, ${ }^{2}$ T. N. M CNEILLY ${ }^{3}$ \& R. J. MELLANBY ${ }^{4}$
}

Departments of ${ }^{1}$ Companion Animal Clinical Studies and ${ }^{2}$ Paraclinical Sciences, Faculty of Veterinary Science, University of Pretoria, Pretoria, South Africa, ${ }^{3}$ Moredun Research Institute, Midlothian, UK, ${ }^{4}$ Division of Veterinary Clinical Studies, Royal (Dick) School of Veterinary Studies, Roslin Institute, University of Edinburgh, Midlothian, UK

\section{SUMMARY}

Spirocerca lupi is a nematode that infects the dog's oesophagus and promotes the formation of an inflammatory fibroblastic nodule that progresses to sarcoma in approximately $25 \%$ of cases. Spirocercosis-associated oesophageal sarcoma is an excellent and under-utilized spontaneous model of parasite-associated malignancy. The inflammatory infiltrate of paraffin-embedded, non-neoplastic oesophageal nodules $(\mathrm{n}=46)$, neoplastic nodules (n $=25)$ and normal oesophagus $(\mathrm{n}=14)$ was examined by immunohistochemistry using MAC387 (myeloid cells), CD3 (T cells), Pax5 (B cells) and FoxP3 (T regulatory cells) antibodies. Myeloid cells predominated in 70\% of nodules, in pockets around the worms' migratory tracts and in necroulcerative areas in neoplastic cases. $\mathrm{T}$ cells predominated in $23 \%$ of cases with a focal or diffuse distribution, in the nodule periphery. No significant differences were observed between neoplastic and non-neoplastic stages. FoxP3 + cells were observed in low numbers, not significantly different from the controls. The inflammation in spirocercosis is characterized by pockets of pus surrounded by organized lymphoid foci. There was no evidence of a local accumulation of FoxP3+ cells, unlike many previous studies that have reported an increase in FoxP3 $+\mathrm{T}$ cells in both malignancies and parasite infections. The triggering factor(s) driving the malignant transformation of the spirocercosis-associated chronic inflammatory nodule warrants further investigation.

Keywords CD3, FoxP3, MAC387, Pax5, sarcoma, Spirocerca lupi, T regulatory cells

\section{INTRODUCTION}

Spirocerca lupi is a nematode for which the dog is the final host (1). In the dog, the adult nematode resides in the oesophagus, which results in the formation of an oesophageal nodule. Over time, up to $25 \%$ of these nodules undergo neoplastic transformation (2). Histologically, the sarcoma has been classified as fibrosarcoma, osteosarcoma or anaplastic sarcoma $(3,4)$. The different stages of the spirocercosis-induced oesophageal nodule have recently been described (5). It was proposed that non-neoplastic S. lupi nodules could be divided into two stages: an early inflammatory stage, where the nodule is characterized histologically by fibrocytes and abundant collagen, and a preneoplastic stage, where the nodule is characterized by the presence of activated fibroblasts (more mitoses and a greater proportion of fibroblasts that showed some degree of atypia) and reduced collagen. Both stages are characterized by lympho-plasmacytic inflammation. Finally, the nodule develops into malignant sarcoma (5). This study was the first to describe the high prevalence and severity of the lympho-plasmacytic infiltrates in S. lupi-induced nodules that have often previously been incorrectly classified as granulomas (1). Neutrophils were also very common in the non-neoplastic cases, where they were distributed either diffusely or in purulent foci immediately adjacent to the worm tract(s) and their associated tissue debris. The neoplastic cases generally had less inflammation; the inflammation was predominantly suppurative, and the foci of suppuration were typically confined to necro-ulcerative areas in the tumour.

The finding that $\mathrm{S}$. lupi nodules have a marked lympho-plasmacytic infiltration is important because the association between chronic infection-induced inflammation and cancer is now well described and is thought to be the mechanism responsible for up to $18 \%$ of global cancers (6). In terms of parasite-associated malignancies, three helminth infections have been classified as carcinogenic in humans, namely Schistosoma haematobium, Clonorchis sinensis and Opisthorchis viverrini, and the presence of chronic inflammation induced by parasites or their deposition is considered a key element in their carcinogenesis (6). In dogs, oesophageal sarcoma (excluding 
leiomyosar-coma) is almost invariably associated with S. lupi infections, whereas in human oncogenic helminthassociated neoplasia, the association is limited to only a few of the specific cancer cases (7), making spirocercosis a highly attractive model to study the association between cancer, helminth infection and inflammation.

It is widely accepted that helminths and their antigens induce a Th2 response (8), and although a Th2 response to the parasite is essential for the host to clear the infection, it is imperative that the immune response is well controlled. The Th2 response can be tightly controlled by CD4+ regulatory T cells (Tregs), which are characterized by the expression of CD25 and the intra-cellular forkhead box P3 (FoxP3) transcription factor, secretion of interleukin (IL)-10 and transforming growth factor $\mathrm{b}(\mathrm{TGFb})(8)$. While Tregs are essential in the prevention of autoimmune and allergic diseases via their inhibition of an autopathogenic immune responses, induction of Tregs by helminths can facilitate long-lasting infection (8). Similarly, Tregs can inhibit the anti-tumour immune response (9), and an increase in their number may facilitate tumour development. Numerous clinical studies on human patients with various types of cancer have shown increased Tregs proportions in the peripheral blood, draining lymph nodes and within the tumours (10-14).

FoxP3 + Tregs can be identified in the dog using a cross-reactive, directly conjugated murine FoxP3 antibody (15). As in humans, tumour-bearing dogs were found to have an increased number andor proportions of Tregs in the circulation (15-17), draining lymph nodes (15) and within the tumour (17). The fact that the role of Tregs is well described in both helminth infection and cancer may indicate a potential role in helminth-induced cancer, such as spirocercosis. However, the role of FoxP3+ Tregs in helminth infections in dogs has not been investigated, and the presence of FoxP3 + cells has not been examined by immunohistochemistry in canine tissue.

The primary objective of this study was to characterize the lymphocyte and myeloid infiltrate in S. lupi nodules by immunohistochemistry using antibodies against CD3 (T cells), Pax 5 (B cells) and MAC387 (myeloid cells) $(18,19)$. A secondary objective of the study was to investigate the prevalence of FoxP3+ Tregs in the S. lupi nodule by immunohistochemistry.

\section{MATERIALS AND METHODS}

\section{Case selection}

Seventy-one formalin-fixed, paraffin-embedded, S. lupi-induced oesophageal nodules, collected between 1998 and 2009, were retrieved from the archives of the Section of Pathology, Faculty of Veterinary Science, University of Pretoria (retrospective study). The samples were collected during necropsy. In most cases, only one sample was collected for diagnostic purposes. In the smaller benign nodules, a transverse section was taken through the entire nodule. One 5- $\mu \mathrm{m}$-thick tissue section per block was stained with haematoxylin and eosin (H\&E) for subsequent histological evaluation. Nodules were classified into neoplastic $(n=25)$ and non-neoplastic $(n=46)$ groups. Only one nodule was selected per dog for subsequent immunohistochemical analyses. If a dog had more than one nodule, the nodule that was most mature or advanced towards neoplastic transformation was selected. In the larger nodules, multiple sections were taken, and the most diagnostic section was selected.

For negative tissue control purposes, 14 sections of normal distal third of dog oesophagus were used. For nine of the $S$. lupi-induced oesophageal nodule cases (five neoplastic and four non-neoplastic), the draining lymph nodes of the distal oesophagus (bronchial) and remote lymph nodes (popliteal) were also collected. The entire lymph nodes were collected, and a transverse section was fixed in paraffin. Lymph node was the positive tissue control for immunohistochemical labelling.

\section{Immunohistochemical labelling of FoxP3, CD3, Pax5 and myeloid/histiocyte antigen MAC387}

Four- $\mu \mathrm{m}$-thick serial sections were cut and mounted on Superfrost-Plus glass slides (Thermo Scientific, Epsom, UK) and dried overnight in an oven at $60^{\circ} \mathrm{C}$ to enhance tissue adhesion. Following rehydration, antigen retrieval was performed. For FoxP3, CD3 and Pax5 labelling, heat-induced epitope retrieval was performed by autoclaving at $121^{\circ} \mathrm{C}$ for $10 \mathrm{~min}$ in $10 \mathrm{mM}$ citrate buffer $\mathrm{pH} \mathrm{6-0.} \mathrm{For} \mathrm{MAC387} \mathrm{labelling,} \mathrm{sections} \mathrm{were} \mathrm{pretreated} \mathrm{with} \mathrm{protein-}$ ase $\mathrm{K}$ (Dako, Rochester, NY, USA) for $5 \mathrm{~min}$ at $25^{\circ} \mathrm{C}$. The sections were washed twice in phosphate-buffered saline (PBS) and again in PBS containing 0-5\% Tween 80 (PBST80) for 5 min. Endogenous peroxidase activity was quenched by incubating the tissue sections with 0-3\% hydrogen peroxide in PBST80 for 20 min at room temperature (RT). Following two washes in PBST80, slides were loaded into a Sequenza immunostaining centre (Thermo Scientific). Nonspecific tissue antigens were blocked by incubation in $25 \%$ normal goat serum (NGS) in PBS/0$5 \%$ Tween 80 (PBS/T80) for $1 \mathrm{~h}$ at RT prior to incubation overnight at $4{ }^{\circ} \mathrm{C}$ with the following primary antibodies: $1: 100$ dilution of rat anti-mouse/rat FoxP3 monoclonal antibody (mAb) (FJK-16s; eBioscience, San Diego, CA, USA); $1: 200$ dilution of polyclonal rabbit anti-human CD3 antibody (Dako); and $1: 50$ dilution of mouse antihuman Pax-5 mAb (clone 24; BD Biosciences). MAC 387 antibodies were incubated for $1 \mathrm{~h}$ at $25^{\circ} \mathrm{C}: 1: 400$ dilution of mouse anti-human Myeloid/Histiocyte Antigen mAb (clone MAC387; Dako). Control antibodies included Rat IgG2a isotype control mAb (eBioscience), mouse anti-Border disease virus p125/p80 mAb VPM21 
and purified rabbit immunoglobulin (Sigma-Aldrich, St. Louis, MO, USA), for rat, mouse and rabbit primary antibodies, respectively. All antibodies were diluted in PBS/T80 containing 10\% NGS.

Slides were washed twice in PBS, and the appropriate secondary antibody (peroxidase-labelled anti-mouse or anti-rabbit EnVision $^{\mathrm{TM}}+$ reagent, Dako) was applied to sections for 30 min at RT. After a final PBS wash, sections were incubated with 3,3'-diaminobenzidine (DAB) for 7-5 min at RT, washed in distilled water, counterstained with haematoxylin, dehydrated and mounted in Shandon synthetic mountant (Thermo Scientific).

\section{Scoring of immunohistochemistry labelling}

Each nodule was scanned under the light microscope. The initial scanning was performed with a wide-angle lens at low power (x20), and the following data were recorded: the predominant inflammatory cell type, the distribution of the cell infiltrate (diffuse or focal/multifocal) and the location of the infiltrate within the nodule (peripheral, central or both). $\mathrm{CD} 3+$ and Pax5 + cells tended to occur in a focal/multifocal distribution pattern in the sections, and the foci of $\mathrm{CD} 3+$ and Pax5+ cells were counted in the most active $\mathrm{x} 20$ field (the field with the highest number of foci). CD3+ and Pax5+ infiltrates were subjectively scored 0-3 (Table 1). MAC387+ infiltrates were also scored 0-3; however, MAC387+ cells occurred more diffusely in sections, either evenly distributed or in patches, and therefore, the scoring system was slightly different (Table 2). Numbers of FoxP3+ cells were counted in 10 nonoverlapping x400 fields (five peripheral and five central fields per oesophageal nodule using a $0 Æ 0625 \mathrm{~mm}^{2}$ graticule). In the normal oesophagus control group and lymph nodes, five nonoverlapping x400 fields were counted. Counting was confined to $\mathrm{CD} 3+$ areas.

\section{Statistical analyses}

Statistical analyses were performed with GRAPHPAD PRISM (GraphPad Software, Inc. CA, USA). The difference in prevalence and distribution of the different proportions of cell types was tested using the chi-square test. The differences between the scores of the different types of infiltrate were tested for significance between all groups using a Kruskal-Wallis test, followed by Dunn's post hoc test. P values of $<0 Æ 05$ were considered significant.

\section{RESULTS}

Myeloid cells predominated in $70 \%$ of cases, while T cells predominated in $23 \%$ of cases. In the remaining $7 \%$ of cases, the number of $\mathrm{T}$ cells and myeloid cells was approximately equal. There was no difference in the proportion of myeloid and $\mathrm{T}$ cells between the neoplastic and non-neo-plastic groups $(\mathrm{P}=0 Æ 27)$. When cells were present in normal oesophageal sections, they were diffusely scattered and myeloid and $\mathrm{T}$ cells tended to occur in equal proportions (Table 3). The inflammatory score of all cell types was significantly higher $(\mathrm{P}<0 Æ 05)$ in the spirocercosis groups compared to the control group, but was not different between the neoplastic and nonneoplastic groups (Tables 4-6).

Myeloid cells were most commonly confined to massive diffuse pockets around worm migratory tracts (Figure 1a) and to necro-ulcerative areas, the latter especially in neoplastic cases (Figure 1b). Most cases had massive diffuse areas that could not be counted. To a lesser extent, myeloid cells were diffusely scattered throughout the nodules (Table 4).

T cells occurred diffusely (Figure 1c) or in a focal/multi-focal (Figure 1d) distribution pattern, predominantly at the periphery of the nodule (Table 5 ). The number of foci in the most active $\cdot 20$ field ranged from 0 to 18 . B cells followed the same distribution within the nodule as T cells (Table 6), but there were fewer of them (Table 7), and they were more confined to focal/multifocal areas (Figure 1e).

FoxP3 3 cells were detected in $30 \%$ of nodules ( $32 \%$ of neoplastic cases and $28 \%$ of the non-neoplastic cases), especially in $\mathrm{T}$ cell foci, but they were not observed in the normal oesophagus. In most of the S. lupi cases where FoxP3 + cells were detected, the number of cells was very low and was not significantly different from the normal oesophagus, where no FoxP3+ cells were detected (Table 8). However, three cases (one non-neoplastic and two neo-plastic) contained a high power field with more than $10 \mathrm{FoxP} 3+$ cells (up to 47 cells $0 Æ 0625 \mathrm{~mm}^{2}$ in a selected high power field; Figure 1f).

High numbers of FoxP3+ cells were observed in the lymph nodes (Table 9, Figure 1g), but no difference was observed between the bronchial and popliteal nodes and between the neoplastic draining $(86 Æ 44 € 34 Æ 39$, mean $€$ -SD $\left.0 Æ 0625 \mathrm{~mm}^{2}\right)$ and non-neoplastic draining nodes $(85 Æ 95 € 54 Æ 55)$. These FoxP3+ cells were confined to $\mathrm{CD} 3+$ areas (Figure 1h).

\section{DISCUSSION}

The current study revealed that the predominant inflammatory cells in S. lupi oesophageal nodules are of myeloid 
lineage. These cells were identified by a MAC387 antibody, which does not enable differentiation between the different types of myeloid cells. However, based on the histological appearance, the vast majority of myeloid cells were neutrophils. These neutrophils formed pockets of pus around the worm, or they were confined to necroulcerative areas in the neoplastic nodules. Alternatively, neutrophils occurred diffusely throughout the nodules. The lymphocytic infiltrates had a prominent focal/multifocal distribution pattern (compared to the myeloid cells), and they were usually peripherally located within nodules. However, in the majority of cases, lymphocytes occurred in a mixed pattern, namely focal/multifocal and diffuse. The relative proportions of leucocytes within S. lupi nodules were different to our initial observations in H\&E-stained sections (5). This finding shows the importance of further identification and quantification of cells using immunohistochemistry. There are two possible explanations for the observed difference. First, in the current study, plasma cells were not labelled, but plasma cell-rich foci in H\&E-stained sections would have been incorporated into the lympho-plasmacytic scoring in the previous study. Also, the focal / multifocal distribution pattern of the lympho-plasmacytic reaction, which frequently made it the predominant cell infiltrate in certain fields, may have biased our scoring over the whole slide in the previous study. We could also not demonstrate the difference in the inflammation score and composition of the cell infiltrate between neoplastic and non-neoplastic cases that we previously observed (5).

Myeloid cells and especially neutrophils play a major role in the innate local inflammatory response in the spirocercosis-induced nodule. Myeloid cells can have an important role in cancer induction by generating proteases, free radical and nitrogen species that can cause oxidative damage to the DNA (6). They can also play a crucial role in establishing cytokine-induced tumour rejection (20), and they also play a major part in endothelium-mediated lymphocyte trafficking and antigen presentation. Polymorphonuclear cells have shown both pro- and anti- inflammatory activities. They may participate in the switch to immune suppression by Th2 and Tregs through up-regulation of IL-10 (20). More recently, neutrophils have been shown to play a pivotal role in the regulation of the inflammatory response against cancer (21). For instance, neutrophils can be induced by serum amyloid A (SAA)1 to secrete IL-10 that induces suppression of immune surveillance (22).

In the present study, $\mathrm{T}$ cells outnumbered B cells. To further differentiate between the different T-cell types, especially into CD4+ or CD8+ cells, frozen sections (which were not available in this study) would be necessary. Based on the current knowledge of helminth-associated chronic inflammation, these cells are likely to be Th2 CD4+ cells (8). Th2 responses are generally correlated with suppressed cell-mediated immune response and with enhanced tumour promotion and progression. B-cell response is often associated with Th2 cell response and also with increased risk for neoplastic progression (23-25). Additionally, immunoglobulins and more specifically immune complexes are regarded as tumour-promoting (23). The humoral response in spirocercosis warrants further investigation for its role in the carcinogenesis in spirocercosis and also for the potential use of serology as a diagnostic tool in this disease.

This study reports for the first time an approach to the identification of FoxP3+ cells in excised diseased canine tissue. We hypothesized that Tregs will be present in high numbers in the spirocercosis-induced nodules and that their numbers will increase as the nodule progressed towards sarcoma, but although FoxP3+ cells were found in large numbers within CD3+ regions of lymph nodes, they were rarely observed in S. lupi-associated oesophageal nodules and when present, they were usually in very small numbers. This is surprising considering the wide range of studies that have found increased numbers and proportions of FoxP3+ Tregs within tumours in humans (26-28) and murine models (29) including models of fibrosarcoma (30). The only other study to examine Tregs within canine tumours found similar results to the many other studies of human tumours and experimental cancer models. They reported that the percentage of FoxP3 + CD4 + cells in dogs with malignant melanoma was significantly increased in the blood compared with healthy control dogs, and the percentage of FoxP3 + CD4+ cells within tumours compared to blood was also significantly increased (31). Therefore, this study clearly demonstrates that the developing dogma that FoxP3 $+\mathrm{T}$ cells are highly prevalent in tumour-associated inflammation is not universally true and emphasizes that malignant transformation can still occur in the absence of immunosuppressive FoxP3 $+\mathrm{T}$ cells. It is in agreement with the canine literature on sarcoma (16), especially osteosarcoma (32). Interestingly, in humans with Ewing's sarcoma, there was also no infiltration of FoxP3+ cells into the tumours, whereas in patients with metastases, the number of FoxP3+ cells only increased in the bone marrow (33). The fact that a large number of positive cells were observed in a few cases, as well as in lymph nodes, but not in the iso- or tissue controls, excludes technical error. Moreover, all samples were fixed by the same method (formalin-fixed and paraffin-embedded), and the nine positive controls (lymph nodes) originate from nine of the study cases. Therefore, it seems feasible that there is a real difference in the immune response to sarcomas (especially in dogs), compared to other tumours, especially melanomas.

The possible role of Tregs in the pathogenesis of spirocercosis-induced sarcoma is especially intriguing, because of the well-documented role of Tregs in helminth infection. In chronic helminth infection (and spirocercosisinduced inflammation is, indeed, chronic) Tregs reduce the intensity of the infection (8). There is evidence that the increased Tregs response facilitates long-lasting chronic inflammation that reduces auto-immunity and allergy in 
infected subjects (34). This notion is part of the proposed mechanism of what is known as the 'hygiene hypothesis' that describes the association between of helminth infection and low incidence of autoimmunity (35). The Tregsinduced increased 'self-tolerance' may reduce anti-tumour immunity, and this could potentially be the link between spirocercosis and tumour formation. It appears, however, that although FoxP3+ cells were circulating in lymphatics around S. lupi nodules, 'homing' into the nodules did not take place. The low number of FoxP3+ cells does not entirely preclude their potential role in local or systemic immune inhibition in spirocercosis, but functional assays are required. However, it is important to acknowledge that although FoxP3 is the gold standard marker of murine Tregs (36), there are many types of Tregs that do not express FoxP3, for example, the widely described Tr1 cells (36). These cells also regulate the immune response through secretion of IL-10 and TGFb, and it is possible that they are involved in immunoregulation in spirocercosis.

One weakness of the current study is that tissue sampling was not standardized. Unfortunately, this is the reality when utilizing clinical cases, especially in a retrospective study. The cell counting was also limited to a single section. However, because this is primarily a descriptive study, we believe the results are valid. More over, in the search for Tregs, we tried to augment the chances for finding them by limiting the count to areas with high CD3+ cells presence (based on the lymph node findings and pilot observations), and yet, we met with limited success. Therefore, the lack of FoxP3+ cells in most of the $\mathrm{S}$. lupi nodules seems reliable. The study also provides unique in situ morphologic picture of the FoxP3+ infiltrate, in which no dog study has reported. The key question in spirocercosis remains: What is the trigger for the transformation from the chronic inflammatory, fibroblastic nodule to sarcoma? This transformation may be triggered by the inflammatory response or, alternatively, via worm excretory/secretory (ES) products. Recent studies have shown that ES products from O. viverrini, a helminth that induces cholangiocarcinoma in humans, increased fibroblast cell proliferation in cell cultures (37). However, the theory of stimulation of cells in the nodule by the worm does not completely exclude the inflammatory mediation hypothesis, because other studies have shown that O. viverrini ES products up-regulate the expression of $\mathrm{TGFb}$, which may represent an indirect carcinogenic effect via immunosuppression (38). Many studies have elucidated the role played by helminth ES products in the modulation of the immune response, especially via the inhibition of innate cell functions and induction of a Th2 response (39). Such mechanisms clearly warrant further investigation whether we are to understand the pathogenesis of S. lupi-induced sarcoma.

\section{ACKNOWLEDGEMENTS}

This study was funded by Petplan Charitable Trust. The authors would like to thank Jeanie Finlayson, Dr Julio Benavides and the Histopathology laboratory at Moredun Research Institute, and Neil McIntyre at the Royal (Dick) School of Veterinary Studies, for assistance with immuno-histochemical staining and analysis. 


\section{REFERENCES}

1. $\quad$ Bailey WS. Spirocerca lupi: a continuing inquiry. J Parasitol 1972; 58: 3-22.

2. Dvir E, Kirberger RM and Malleczek D. Radiographic and computed tomographic changes and clinical presentation of spirocercosis in the dog. Vet Radiol Ultrasound 2001; 42: 119129.

3. Ranen E, Dank G, Lavy E, Perl S, Lahav D and Orgad U. Oesophageal sarcomas in dogs: histological and clinical evaluation. Vet J 2008; 178: 78-84.

4. Ranen E, Lavy E, Aizenberg I, Perl S and Harrus S. Spirocercosis-associated esophageal sarcomas in dogs. A retrospective study of 17 cases (1997-2003). Vet Parasitol 2004; 119: 209-221.

5. Dvir E, Clift SJ and Williams MC. Proposed histological progression of the Spirocerca lupiinduced oesophageal lesion in dogs. Vet Parasitol 2010; 168: 71-77.

6. Vennervald BJ and Polman K. Helminths and malignancy. Parasite Immunol 2009; 31: 686696.

7. Herrera LA, Benitez-Bribiesca L, Mohar A and Ostrosky-Wegman P. Role of infectious diseases in human carcinogenesis. Environ Mol Mutagen 2005; 45: 284-303.

8. Maizels RM, Pearce EJ, Artis D, Yazdanbakhsh M and Wynn TA. Regulation of pathogenesis and immunity in helminth infections. J Exp Med 2009; 206: 2059-2066.

9. $\quad$ Beyer M and Schultze JL. Regulatory T cells in cancer. Blood 2006; 108: 804-811.

10. Curiel TJ, Coukos G, Zou L et al. Specific recruitment of regulatory $\mathrm{T}$ cells in ovarian carcinoma fosters immune privilege and predicts reduced survival. Nat Med 2004; 10: 942949.

11. Heimberger AB, Abou-Ghazal M, Reina-Ortiz C et al. Incidence and prognostic impact of FoxP3+ regulatory T cells in human gliomas. Clin Cancer Res 2008; 14: 5166-5172.

12. Liyanage UK, Moore TT, Joo HG et al. Prevalence of regulatory T cells is increased in peripheral blood and tumor microenvironment of patients with pancreas or breast adenocarcinoma. J Immunol 2002; 169: 2756-2761.

13. Wolf AM, Wolf D, Steurer M, Gastl G, Gunsilius E and Grubeck-Loebenstein B. Increase of regulatory T cells in the peripheral blood of cancer patients. Clin Cancer Res 2003; 9: 606612 .

14. Woo EY, Chu CS, Goletz TJ et al. Regulatory CD4(+)CD25(+) T cells in tumors from patients with early-stage non-small cell lung cancer and late-stage ovarian cancer. Cancer Res 2001; 61: 4766-4772.

15. Biller BJ, Elmslie RE, Burnett RC, Avery AC and Dow SW. Use of FoxP3 expression to identify regulatory $\mathrm{T}$ cells in healthy dogs and dogs with cancer. Vet Immunol Immunopathol 2007; 116: 69-78.

16. O'Neill K, Guth A, Biller B, Elmslie R and Dow S. Changes in regulatory T cells in dogs with cancer and associations with tumor type. $J$ Vet Intern Med 2009; 23: 875-881.

17. Tominaga M, Horiuchi Y, Ichikawa M et al. Flow cytometric analysis of peripheral blood and tumor-infiltrating regulatory $\mathrm{T}$ cells in dogs with oral malignant melanoma. J Vet Diagn Invest 2010; 22: 438-441.

18. Vanherberghen M, Day MJ, Delvaux F, Gabriel A, Clercx C and Peeters D. An immunohistochemical study of the inflammatory infiltrate associated with nasal carcinoma in dogs and cats. J Comp Pathol 2009; 141: 17-26.

19. Willmann M, Mullauer L, Guija de Arespacochaga A, Reifinger M, Mosberger I and Thalhammer JG. Pax5 immunostaining in paraffin-embedded sections of canine non-Hodgkin lymphoma: a novel canine pan pre-B- and B-cell marker. Vet Immunol Immunopathol 2009; 128: $359-365$.

20. Di Carlo E, Forni G, Lollini P, Colombo MP, Modesti A and Musiani P. The intriguing role of polymorphonuclear neutrophils in antitumor reactions. Blood 2001; 97: 339-345.

21. Mattarollo SR and Smyth MJ. A novel axis of innate immunity in cancer. Nat Immunol; 11: 981-982.

22. De Santo C, Arscott R, Booth S et al. Invariant NKT cells modulate the suppressive activity of IL-10-secreting neutrophils differentiated with serum amyloid A. Nat Immunol; 11: 10391046.

23. Tan TT and Coussens LM. Humoral immunity, inflammation and cancer. Curr Opin Immunol 2007; 19: 209-216.

24. Shah S, Divekar AA, Hilchey SP et al. Increased rejection of primary tumors in mice lacking B cells: inhibition of anti-tumor CTL and TH1 cytokine responses by B cells. Int J Cancer 
2005; 117: 574-586.

25. de Visser KE, Korets LV and Coussens LM. De novo carcinogenesis promoted by chronic inflammation is B lymphocyte dependent. Cancer Cell 2005; 7: 411-423.

26. Xue L, Lu HQ, He J et al. Expression of FOXP3 in esophageal squamous cell carcinoma relating to the clinical data. Dis Esophagus 2009.

27. Carreras J, Lopez-Guillermo A, Fox BC et al. High numbers of tumor-infiltrating FOXP3positive regulatory $\mathrm{T}$ cells are associated with improved overall survival in follicular lymphoma. Blood 2006; 108: 2957-2964.

28. Unitt E, Rushbrook SM, Marshall A et al. Compromised lymphocytes infiltrate hepatocellular carcinoma: the role of T-regulatory cells. Hepatology 2005; 41: 722-730.

29. Imai H, Saio M, Nonaka $\mathrm{K}$ et al. Depletion of $\mathrm{CD} 4+\mathrm{CD} 25+$ regulatory $\mathrm{T}$ cells enhances interleukin-2-induced antitumor immunity in a mouse model of colon adenocarcinoma. Cancer Sci 2007; 98: 416-423.

30. Betts G, Twohig J, Van den Broek M, Sierro S, Godkin A and Gallimore A. The impact of regulatory T cells on carcinogen-induced sarcogenesis. Br J Cancer 2007; 96: 1849-1854.

31. Tominaga M, Horiuchi $\mathrm{Y}$, Ichikawa $\mathrm{M}$ et al. Flow cytometric analysis of peripheral blood and tumor-infiltrating regulatory $\mathrm{T}$ cells in dogs with oral malignant melanoma. $J$ Vet Diagn Invest; 22: 438-441.

32. Rissetto KC, Rindt H, Selting KA, Villamil JA, Henry CJ and Reinero CR. Cloning and expression of canine CD25 for validation of an anti-human CD25 antibody to compare T regulatory lymphocytes in healthy dogs and dogs with osteosarcoma. Vet Immunol Immunopathol 2010; 135: 137-145.

33. Brinkrolf $\mathrm{P}$, Landmeier $\mathrm{S}$, Altvater $\mathrm{B}$ et al. A high proportion of bone marrow $\mathrm{T}$ cells with regulatory phenotype $(\mathrm{CD} 4+\mathrm{CD} 25 \mathrm{hiFoxP} 3+)$ in Ewing sarcoma patients is associated with metastatic disease. Int $J$ Cancer 2009; 125: 879-886.

34. Wilson MS and Maizels RM. Regulation of allergy and autoimmunity in helminth infection. Clin Rev Allergy Immunol 2004; 26: 35-50.

35. Maizels RM. Parasite immunomodulation and polymorphisms of the immune system. $J$ Biol 2009; 8: 62 .

36. Rouse BT. Regulatory T cells in health and disease. J Intern Med 2007; 262: 78-95.

37. Thuwajit $\mathrm{C}$, Thuwajit $\mathrm{P}$, Kaewkes $\mathrm{S}$ et al. Increased cell proliferation of mouse fibroblast NIH-3T3 in vitro induced by excretory/secretory product(s) from Opisthorchis viverrini. Parasitology 2004; 129: 455-464.

38. Thuwajit $\mathrm{C}$, Thuwajit $\mathrm{P}$, Uchida $\mathrm{K}$ et al. Gene expression profiling defined pathways correlated with fibroblast cell proliferation induced by Opisthorchis viverrini excretory/secretory product. World J Gastroenterol 2006; 12: 3585-3592.

39. Hewitson JP, Grainger JR and Maizels RM. Helminth immunoregulation: the role of parasite secreted proteins in modulating host immunity. Mol Biochem Parasitol 2009; 167: 1-11. 
Figure 1
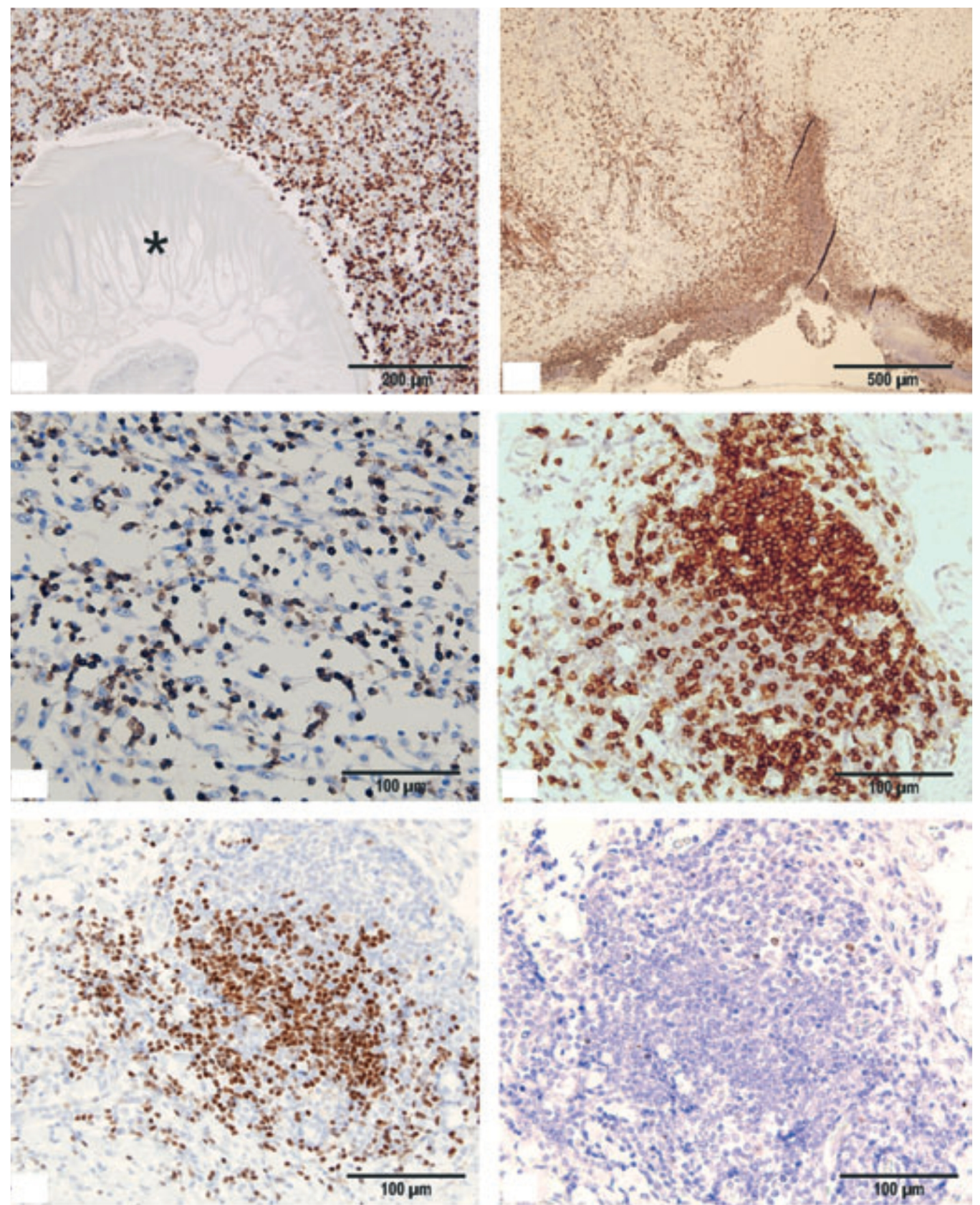

\& tat

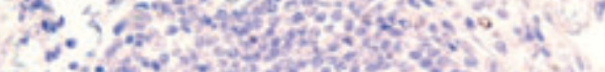
8.
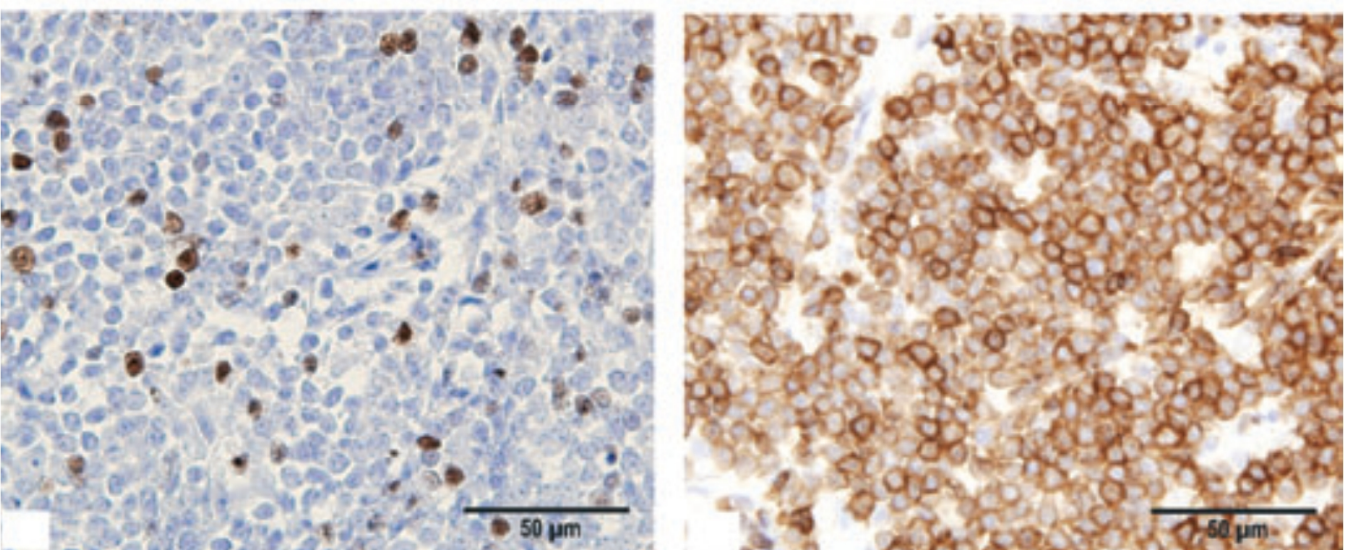
A: MAC387+ leukocytes, predominantly neutrophils, around a Spirocerca lupi parasite (asterisk) in a non-neoplastic esophageal nodule.

B: MAC387+ leukocytes, predominantly neutrophils, in an extensive area of ulceration in a Spirocerca lupi-induced esophageal osteosarcoma.

C: Focal/nodular distribution of Pax5+ B lymphocytes in a Spirocerca lupi-induced esophageal undifferentiated sarcoma.

C: Diffuse distribution of CD3+ $\mathrm{T}$ lymphocytes in a Spirocerca lupi-induced esophageal undifferentiated sarcoma.

D: Focal/nodular distribution of CD3+ $\mathrm{T}$ lymphocytes in a Spirocerca lupi-induced esophageal undifferentiated sarcoma.

E: Pax5+ B lymphocytes in the same lymphoid focus at the periphery of Spirocerca lupi-induced esophageal undifferentiated sarcoma as is shown in D.

F: FoxP3+ cells in the same lymphoid focus at the periphery of Spirocerca lupi-induced esophageal undifferentiated sarcoma as is shown in D and E.

G: FoxP3+ cells in a bronchial lymph node, draining the distal esophageal osteosarcoma referred to in figure D.

H: CD3 + T lymphocytes in the same area of bronchial lymph node as shown in figure G.

Table 1: Scoring system for CD3+ and Pax5+ infiltrates

\begin{tabular}{|l|l|l|}
\hline score & Infiltrate intensity (x400 fields) & $\begin{array}{l}\text { Number of foci (x20 } \\
\text { fields) }\end{array}$ \\
\hline 0 & scant or absent & 0 \\
\hline 1 & positive cells evident but not in all fields & $\leq 1$ \\
\hline 2 & positive cells present in all fields but markedly fewer in number than & $\leq 3$ \\
\hline 3 & other inflammatory cells & \\
\hline
\end{tabular}


Table 2: Scoring system for MAC387+ infiltrates

\begin{tabular}{|l|l|}
\hline score & Infiltrate intensity (x400 fields) \\
\hline 0 & scant or absent \\
\hline 1 & positive cells evident but not in all fields \\
\hline 2 & positive cells present in all fields but markedly fewer in number than other inflammatory cells \\
\hline 3 & Positive cells predominant \\
\hline
\end{tabular}

Table 3: Leukocyte prevalence

\begin{tabular}{|l|l|l|l|}
\hline Group & Predominantly & Predominantly CD3 & Equal CD3 and \\
& MAC387 & & MAC387 \\
\hline Neoplastic & $72 \%(18 / 25)$ & $24 \%(6 / 25)$ & $4 \%(1 / 25)$ \\
\hline Non-neoplastic & $70 \%(32 / 46)$ & $21.5 \%(10 / 46)$ & $8.5 \%(4 / 46)$ \\
\hline Normal esophagus & $43 \%(6 / 14)$ & $50 \%(7 / 14)$ & $7 \%(1 / 14)$ \\
\hline
\end{tabular}

Table 4: Nodule distribution and score of MAC387+ cells

\begin{tabular}{|c|c|c|c|c|c|c|c|c|c|}
\hline \multirow{2}{*}{ Group } & \multicolumn{3}{|c|}{$\begin{array}{l}\text { Pattern of the infiltrate } \\
\text { distribution }\end{array}$} & \multicolumn{3}{|c|}{ Location within the nodule } & \multirow{2}{*}{$\begin{array}{l}\text { No } \\
\text { cells }\end{array}$} & \multicolumn{2}{|l|}{ Score } \\
\hline & Even & Patchy & Mixed & Peripheral & Central & Both & & Mean & Median \\
\hline Neoplastic & $\begin{array}{l}88 \% \\
(22 / 25)\end{array}$ & $\begin{array}{l}4 \% \\
(1 / 25)\end{array}$ & $\begin{array}{l}8 \% \\
(2 / 25\end{array}$ & $\begin{array}{l}60 \% \\
(15 / 25)\end{array}$ & $\begin{array}{l}8 \% \\
(2 / 25)\end{array}$ & $\begin{array}{l}32 \% \\
(8 / 46)\end{array}$ & $0 / 46$ & $\begin{array}{l}2.04 \\
\pm \\
0.98\end{array}$ & $2(1-3)$ \\
\hline $\begin{array}{l}\text { Non- } \\
\text { neoplastic }\end{array}$ & $\begin{array}{l}98 \% \\
(45 / 46)\end{array}$ & $\begin{array}{l}2 \% \\
(1 / 46)\end{array}$ & $0 / 46$ & $6 \%(3 / 46)$ & $\begin{array}{l}22 \% \\
(10 / 46)\end{array}$ & $\begin{array}{l}72 \% \\
(33 / 46)\end{array}$ & $0 / 46$ & $\begin{array}{l}2.37 \\
\pm 0.9\end{array}$ & $3(1-3)$ \\
\hline $\begin{array}{l}\text { Normal } \\
\text { esophagus }\end{array}$ & $\begin{array}{l}50 \% \\
(7 / 14)\end{array}$ & $\begin{array}{l}1 / 14 \\
(7 \%)\end{array}$ & $0 / 14$ & NA & NA & NA & $\begin{array}{l}43 \% \\
(6 / 14)\end{array}$ & $\begin{array}{l}0.57 \\
\pm \\
0.51 *\end{array}$ & $1(0-1)$ \\
\hline
\end{tabular}

*The score of the control was significantly $(<0.05)$ lower compared to the spirocercosis groups' scores using Kruskal-Wallis Test, followed by Dunn's post-hoc test. 
Table 5: Nodule distribution and score of $\mathrm{CD3}+$ cells

\begin{tabular}{|c|c|c|c|c|c|c|c|c|c|c|c|}
\hline \multirow{2}{*}{ Group } & \multicolumn{3}{|c|}{ Pattern of the infiltrate distribution } & \multicolumn{3}{|c|}{ Location within the nodule } & \multirow{2}{*}{$\begin{array}{l}\text { No } \\
\text { cells }\end{array}$} & \multicolumn{2}{|c|}{ Foci number } & \multicolumn{2}{|l|}{ Score } \\
\hline & Diffuse & Focal/multifocal & Mixed & Peripheral & Central & Both & & Mean & Median $^{\dagger}$ & Mean & Median \\
\hline Neoplastic & $\begin{array}{l}24 \% \\
(6 / 25)\end{array}$ & $\begin{array}{l}12 \% \\
(3 / 25)\end{array}$ & $\begin{array}{l}48 \% \\
(12 / 25)\end{array}$ & $\begin{array}{l}48 \% \\
(12 / 25)\end{array}$ & 0 & $\begin{array}{l}36 \% \\
(9 / 25)\end{array}$ & $\begin{array}{l}16 \% \\
(4 / 25)\end{array}$ & $\begin{array}{l}3.56 \\
\pm \\
4.69\end{array}$ & $1(0-16)$ & $\begin{array}{l}1.56 \\
\pm \\
1,21\end{array}$ & $1(0-3)$ \\
\hline $\begin{array}{l}\text { Non- } \\
\text { neoplastic }\end{array}$ & $\begin{array}{l}52 \% \\
(24 / 46)\end{array}$ & $\begin{array}{l}13 \% \\
(6 / 46)\end{array}$ & $\begin{array}{l}33 \% \\
(15 / 46)\end{array}$ & $\begin{array}{l}48 \% \\
(22 / 46)\end{array}$ & $\begin{array}{l}4.5 \% \\
(2 / 46)\end{array}$ & $\begin{array}{l}45.5 .5 \% \\
(21 / 46)\end{array}$ & $\begin{array}{l}2 \% \\
(1 / 46)\end{array}$ & $\begin{array}{l}2.68 \\
\pm \\
4.04\end{array}$ & $1(0-18)$ & $\begin{array}{l}1.78 \\
\pm \\
0.94\end{array}$ & $2(0-3)$ \\
\hline $\begin{array}{l}\text { Normal } \\
\text { esophagus }\end{array}$ & $\begin{array}{l}43 \% \\
(6 / 14)\end{array}$ & $0 / 14$ & $0 / 14$ & NA & NA & NA & $\begin{array}{l}57 \% \\
(8 / 14)\end{array}$ & 0 & 0 & $\begin{array}{l}0.43 \\
\pm \\
0.51^{*}\end{array}$ & $0(0-1)$ \\
\hline
\end{tabular}

$\dagger 2$ cases in the non-neoplastic group had focally extensive areas of cell infiltrate that could not be counted

* The score of the control was significantly $(<0.05)$ lower compared to the spirocercosis groups' scores using Kruskal-Wallis Test, followed by Dunn's post-hoc test. 
Table 6: Nodule distribution and score of Pax5+ cells

\begin{tabular}{|c|c|c|c|c|c|c|c|c|c|c|c|}
\hline \multirow{2}{*}{ Group } & \multicolumn{3}{|c|}{ Pattern of the infiltrate distribution } & \multicolumn{3}{|c|}{ Location within the nodule } & \multirow{2}{*}{$\begin{array}{l}\text { No } \\
\text { cells }\end{array}$} & \multicolumn{2}{|c|}{ Number of foci } & \multicolumn{2}{|l|}{ Score } \\
\hline & Diffuse & Focal/multifocal & Mixed & Peripheral & Central & Both & & Mean & Median & Mean & Median \\
\hline Neoplastic & $\begin{array}{l}8 \% \\
(2 / 25)\end{array}$ & $\begin{array}{l}20 \% \\
(5 / 25)\end{array}$ & $\begin{array}{l}24 \% \\
6 / 25\end{array}$ & $\begin{array}{l}44 \% \\
(11 / 25)\end{array}$ & $0 / 25$ & $\begin{array}{l}8 \% \\
(2 / 25)\end{array}$ & $\begin{array}{l}48 \% \\
(12 / 25)\end{array}$ & $\begin{array}{l}2.44 \\
\pm \\
3.91\end{array}$ & $\begin{array}{l}1 \quad(0- \\
16)\end{array}$ & $\begin{array}{l}0.96 \\
\pm \\
1.14\end{array}$ & $1(0-3)$ \\
\hline $\begin{array}{l}\text { Non- } \\
\text { neoplastic }\end{array}$ & $\begin{array}{l}28 \% \\
(13 / 46)\end{array}$ & $\begin{array}{l}33 \% \\
(15 / 46)\end{array}$ & $\begin{array}{l}13 \% \\
(6 / 46)\end{array}$ & $\begin{array}{l}45.5 \% \\
(21 / 46)\end{array}$ & $\begin{array}{l}4.5 \% \\
(2 / 46)\end{array}$ & $\begin{array}{l}24 \% \\
(11 / 46)\end{array}$ & $\begin{array}{l}26 \% \\
(12 / 46)\end{array}$ & $\begin{array}{l}1.8 \pm \\
2.62\end{array}$ & $0(0-1)$ & $\begin{array}{l}1.15 \\
\pm \\
1.07\end{array}$ & $1(0-3)$ \\
\hline $\begin{array}{l}\text { Normal } \\
\text { esophagus }\end{array}$ & $0 / 14$ & $0 / 14$ & $0 / 14$ & NA & NA & NA & $\begin{array}{l}100 \% \\
(14 / 14)\end{array}$ & 0 & 0 & $0 *$ & 0 \\
\hline
\end{tabular}

* The score of the control was significantly $(<0.05)$ lower compared to the spirocercosis groups' scores using Kruskal-Wallis Test, followed by Dunn's post-hoc test. 
Table 7: Lymphocyte prevalence in the different study groups

\begin{tabular}{|l|l|l|l|}
\hline Group & Predominantly CD3 & Predominantly Pax5 & Equal prevalence \\
\hline Neoplastic & $80 \%(20 / 25)$ & $0 / 25$ & $20 \%, 5 / 25$ \\
\hline Non-neoplastic & $78 \%(36 / 46)$ & $4.5 \%(2 / 46)$ & $17.5 \%, 8 / 46$ \\
\hline Normal esophagus & $100 \%(14 / 14)$ & $0 / 14$ & $0 / 14$ \\
\hline
\end{tabular}

Table 8: The number of FoxP3+ cells per $0.0625 \mathrm{~mm}^{2}$ in the different groups

\begin{tabular}{|l|l|l|l|l|}
\hline \multirow{4}{*}{ Group } & \multicolumn{2}{|l|}{ FoxP3+ cells } & Central \\
\cline { 2 - 5 } & Peripheral & & \multicolumn{2}{l|}{} \\
\cline { 2 - 5 } & Mean \pm STD & Median (range) & Mean \pm STD & Median (range) \\
\hline Neoplastic & $0.73 \pm 3.65$ & $0(0-3)$ & $0.13 \pm 0.39$ & $0(0-2.2)$ \\
\hline Non-neoplastic & $0.69 \pm 1.19$ & $0(0-4.2)$ & $1.34 \pm 5.55$ & $0(0-27.8)$ \\
\hline Normal esophagus & \multicolumn{3}{|l|}{ Mean:0 \pm 0, Median: 0} & \\
\hline
\end{tabular}


Table 9: Number of $T$ regulatory cells per $0.0625 \mathrm{~mm}^{2}$ in the lymph nodes of the different groups

\begin{tabular}{|l|l|l|l|l|}
\hline \multirow{2}{*}{ Group } & \multicolumn{2}{|l|}{ Bronchial lymph nodes (5 fields) } & \multicolumn{2}{l|}{ Popliteal lymph nodes } \\
\cline { 2 - 5 } & Mean \pm STD & Median & Mean \pm STD & Median (range) \\
\hline Neoplastic $(\mathrm{n}=5)$ & $86.44 \pm 34.39$ & $97(38-130)$ & $91.5 \pm 23.59$ & $84.5(65-112)$ \\
\hline $\begin{array}{l}\text { Non-neoplastic } \\
(\mathrm{n}=4)\end{array}$ & $85.95 \pm 54.55$ & $81(33-158)$ & $108.35 \pm 35.8$ & $100(74-156)$ \\
\hline
\end{tabular}

